Open Access

\title{
Welfare and food security response of animal feed and water resource scarcity in Northern Ethiopia
}

\author{
Muuz Hadush ${ }^{1,2}$ (1)
}

\author{
Correspondence: muuz.hadush. \\ gebremichael@nmbu.no; muuz. \\ hadush@mu.edu.et \\ ${ }^{1}$ School of Economics and Business, \\ Norwegian University of Life \\ Sciences (NMBU), Box 5003, 1432 \\ Ås, Norway \\ 2Department of Economics, Mekelle \\ University, P.O. box 451, Mekelle, \\ Ethiopia
}

\begin{abstract}
The scarcity of grazing and water for an animal has a negative effect on household welfare and food security either by affecting livestock production directly, affecting crop or off-farm income due to labor reallocation or through its direct impact on time leisure consumption.

The economic impacts of resource (grazing and water) scarcity on welfare are undermined. Thus, a better understanding that is derived from the factual evidence is required. The first objective of this paper is to explore the link between natural resource scarcity and per capita food consumption expenditure (PCFE) as proxy for welfare and food security followed by the second objective of analyzing whether this effect is uniform across all quantile groups and there is gender differential effect using distance and shadow price as resource scarcity indicators. The paper used a relatively unique data set from a randomly drawn 518 sample farmers in Northern Ethiopia. To address our first objective, we employ the IV two-stage least square estimation for welfare and probit model for food security drawing on non-separable farm household model.

Our estimates show that about $48 \%$ of the households were food secure while $52 \%$ were food insecure. Our results confirmed the theoretical prediction that resource scarcity affects household PCFE and food security adversely as predicted by the downward spiral hypothesis. The results indicate that animal feed and water scarcity have an important impact on welfare and food security. As expected, in aggregate, reducing time spent searching for water per day leads to an increase in PCFE and food security. Similarly, a decrease in time wastage for searching grazing increase PCFE and food security respectively, and an increment of PCFE and food security is achieved by a reduction in crop residue transporting time per day.

The gender differential analysis signals that increasing resource scarcity results in low PCFE and food security, with the male are considerably likely to have less food consumption expenditure and being food insecure more as compared to female households. The total impact of time spent searching for water, grazing, and transporting straw on per PCFE is $-0.142 \%,-0.102 \%$, and $-0.092 \%$, respectively, and decreasing reaching time to a water, grazing, and straw source by 0.6 min will increase PCFE by 354 ETB, 254 ETB, and 229 ETB for the median household. Depending on results from the quantile regression, the effect of water and feed scarcity is not uniform across the food consumption distribution.
\end{abstract}

Keywords: Food consumption, Resource scarcity: welfare, Food security: IV, Probit, Ethiopia 


\section{Introduction}

Many studies have established that the rural poor in developing countries are heavily dependent on local natural resources for their subsistence (e.g., Narain et al. 2008) and that the depletion of these resources hurts the poor more (Khan 2008). Land degradation in Sub-Saharan Africa (SSA) remains a substantial problem to spur rural poverty (Bhattacharya and Innes 2006; Tesfa and Mekuriaw 2014). It directly aggravates poverty, by reducing the availability of environmental goods and services and by increasing the labor input needed to seek for them (Bezabih and Berhane 2014; Lal and Stewart 2010). The critical shortage of those resources has negative implications for agricultural production and food security, particularly for poor people who rely on agriculture as a source of food and spend considerable time to collecting these resources (Mekonnen et al. 2015; Yilma et al. 2011).

Poverty and resource degradation appear to go hand in hand in SSA. Resource degradation by all accounts is rampant in the region. In East Africa, livestock production depends on quantity and quality of grazing feed and water. About $10 \%$ of cropland is used to produce crop residues for feeding livestock, and animals in the extensive system need more water per animal (Bezabih and Berhane 2014). Increasing scarcity of grazing and water for an animal can be a significant burden to households, as grazing and water are a key factor in livestock production. Thus, the scarcity of these resources may directly impact agriculture or indirectly by reallocating factors of production, namely labor from agriculture, food preparation, and leisure activities to searching and collecting these scarce resources. Reductions in agricultural output stemming from less labor input are very likely to have detrimental welfare and food security consequence (Cooke 1998; Kumar and Hotchkiss 1988; Mekonnen et al. 2015). The downward spiral hypothesis states that people in poverty are forced to deplete resources to survive, and this environmental depletion further impoverishes them (Ostrom et al. 1999).

In many studies of Africa, grazing land and water scarcity are frequently mentioned constraints for animal farming activities (Bezabih and Berhane 2014; Tegegne 2012). Grazing and water scarcity may be less problematic in developed countries where there are available substitutes but can have a huge impact on household welfare in developing countries like Ethiopia. Resource depletion, in the country, has contributed to the existing problem of food insecurity and is still a real threat to the agricultural farming (Bewket 2011). World Bank (2012) reported that the cost of environmental degradation is almost $8 \%$ of GDP across countries consisting $40 \%$ of the developing countries. More specifically, environmental depletion, in the study area, has reached a critical stage which poses a major threat to the agriculture production and welfare (Gebregziabher et al. 2008). Households with scarcity may walk longer distances to search and collect these resources, thereby leaving less labor for leisure, food production, and preparation (Bezabih and Berhane 2014; Cooke et al. 2008).

The literature suggests that as a result of increasing resource scarcity, many households increase the time they spend on collecting them. Overall, the scarcity has negative implications for agricultural production and the food security by diminishing households' food supply and incomes, and hence their capacity to achieve food and nutrition (Cooke et al. 2008; Damte et al. 2012; Mekonnen et al. 2015; Tangka and Jabbar 2005). The findings of Cooke (1998) revealed that most of the reallocated time for searching and collecting the scarce resources come from leisure before agricultural labor time is reduced. One early 
analysis conducted by Bandyopadhyay et al. (2011) also indicates that amount of biomass negatively affected rural per capita consumption expenditure in Malawi. Grazing and water scarcity in Ethiopia can affect household welfare in different ways.

Poor farmers may not have access to alternative feed resources and may increase the time spent on searching grazing, water and straw collection, reducing time on farming activities, food preparation, and leisure or household care. Thus, under situations where markets are imperfect, increasing resource scarcity can force households to reallocate labor and thereby reduce welfare. The degree to which labor allocated to an animal feeding and watering takes labor away from agricultural production likely depends on who in the household is engaged in farming when feed collection and grazing takes place (Arnold et al. 2003). It is commonly perceived that children and women are mostly responsible for the collection of feeding and watering an animal and that their scarcity increases the burden on these household members. Individual member's increased labor burden further reduces their overall human welfare (Mekonnen et al. 2015; Tangka and Jabbar 2005).

While the above studies estimate the effect of resource scarcity on time allocation and time reduction for farming, no study we are aware of examining the economic effect of grazing and water scarcity on welfare, which is ultimately what policymakers seek to know (Cooke et al. 2008; Khan 2008; Tangka and Jabbar 2005). This is of potentially relevant but less well studied. In this study, we are able to estimate the effect of grazing, water, and straw scarcity on per capita food consumption expenditure (PCFE) as a proxy for welfare and food security using distance and shadow price ${ }^{1}$ as a proxy for scarcity indicator of these resources by exploiting household survey from Northern Ethiopia. Our analysis is organized around five questions. First, what is the effect of this resource scarcity on welfare (PCFE)? Second, how does resource scarcity affect household food security? Third, is this effect uniform across all quantile groups? Fourth, is there gender differential effect? And, fifth, what is the effect of the scarcity on the total welfare?

In line to this, we hypothesize that the scarcity has a negative effect on households' food security and welfare (PCFE) either by affecting livestock production directly, affecting crop, and off-farm income or through its direct impact on time for leisure consumption drawing on a non-separable farm household model. We also hypothesize that the effect of these scarce resources is not uniform across the food consumption distribution. In aggregate, the principal findings confirmed the theoretical prediction that resource scarcity affects household welfare (PCFE) and food security adversely as predicted by the downward spiral hypothesis. The estimated result from both distance and shadow price revealed that reducing time spent for searching the water, grazing, and collecting crop residue leads to an increase in welfare (PCFE) and food security.

This paper builds on the existing literature in a number of respects. In this paper, we contribute to the literature by using a unique dataset to investigate how the distance to or the shadow price of water, grazing, and crop residue affects PCFE and food security. We are able to estimate causal relationships with our data because, unlike previous studies, we collected information on the entire set of consumption expenditure, along with the distance to grazing, water and crop residue of each household. Furthermore, unlike the previous studies, we use distance and shadow price as a proxy measure of resource scarcity. This paper joins the relatively scarce, empirical literature on this topic in Africa, one that is dominated by South Asian cases such as Nepal. ${ }^{2}$ 


\section{Literature review \\ Review of background}

The contribution of livestock to the world's food supply, family nutrition, incomes, employment, soil fertility, and transport helps for the reduction of food insecurity and poverty (Randolph et al. 2007). Livestock also gives a safety net in the form of liquid assets and a strategy of food production diversification (Freeman et al. 2007). In Ethiopia, the agricultural sector is a cornerstone of the economic and social life of the people. Livestock contribution accounts for $40 \%$ of total agricultural GDP, excluding the values of draft power, manure, and transport service (Asresie and Zemedu 2015). Despite its large population size, the contribution of livestock production to agriculture is deteriorating (Ilyin 2011). Livestock production in Ethiopia depends on the quantity of grazing feed and water (Bezabih and Berhane 2014).This sector is a key player in increasing water use and water depletion (Steinfeld et al. 2006).

Ethiopia is a home of 35 million tropical livestock unit (TLU), and on average, one TLU requires about $25 \mathrm{l}$ of water per day and the total daily water requirement for livestock is estimated at 875 million liters amounting to about 320 billion liters per year. Total grazing land in Tigrai is estimated to be $47,431 \mathrm{~km}^{2}$ while tropical livestock unit (TLU) per $\mathrm{km}^{2}$ of grazing land was increased from 44,000 TLU in 2001/2002 to 55,000 TLU in $2007 / 2008$. Thus, TLU per $\mathrm{km}^{2}$ grazing land in the region is above half for each year due to greater population density, larger herd sizes, and relatively fixed grazing land resources (Tilahun and Schmidt 2012). Both human and livestock suffer from its shortage. Most of the year, animals have to walk long distances in search of water. Major feed resources, in Ethiopia, are crop residues and natural pasture, but their availability is gradually declining as a result of crop expansion, settlement, and land degradation (Gebremedhin 2009; Yimer 2005).

The case study by Belay et al. (2013) indicated that the most important problems of livestock production perceived were feed shortage (100\%) and water shortage (27\%) during the dry season in Ethiopia. Feed and water deficits start in December, when the natural pastures are at their lowest quantity and the supply of stored crop residues is starting to diminish (Sileshi et al. 2003). In the study region, Gebremedhin (2009) and Yimer (2005) also revealed that natural grazing is dimin-

ishing over time due to the high degree of degradation, resulting in high TLU per $\mathrm{km}^{2}$ of grazing land. The estimated crop residues are found to be about $1,229,651$ tons dry matter/year while the region has an estimated 878,322 ha of arable land available for crop production, contributing about $45 \%$ of the animal feed demand. Felleke and Geda (2001) stated that $73 \%$ of the feed is provided from natural grazing, $14 \%$ from crop residues, and the remaining $13 \%$ from other feed sources. A recent study of Bishu (2014) in Tigrai indicated that there is water shortage for livestock drinking (34\%) and feed shortages (7\%). There is also a shortage of labor for livestock management (Tegegne 2012).

\section{Empirical literature}

Dasgupta (2007) warns that the average per capita consumption level may decline with degradation of resources. Aggrey et al. (2010) showed that shortage of firewood and fuelwood were positively linked with poverty in Uganda. The findings of Khan (2008) 
in Pakistan supported that environmental degradation hurts the poor more. The study of Kumar and Hotchkiss (1988) suggested that shortage of firewood has adverse effects on agricultural production, food consumption, and nutrition in Nepal. Poor farmers, who are directly dependent on these local natural resources, are highly affected by the resource scarcity. Cooke's (1998) result revealed that a reallocation of time away from leisure occurred as environmental goods become scarcer in Nepal In addition, the findings of Tangka and Jabbar (2005) in Kenya shows that feed scarcity increases livestock traveling distances in search of feed and water that increase household time for collection, resulting in lower livestock and crop output which further diminishes households' food and nutrition security.

Likewise, Cooke et al. (2008) found a negative effect of resource scarcity on health, labor burden, and agriculture in Nepal. Bhattacharya and Innes (2006) highlighted that forest degradation spurs rural poverty in Sub-Saharan Africa. According to the study of Bandyopadhyay et al. (2011) in Malawi, more time spent on scarce fuelwood collection was associated with negative welfare. Baland et al. (2010) in their result indicate that an increase in firewood collection time lowers living standards of households in Nepal. The study of Aluko (2004) showed that deterioration in the quality of life increases with increasing environmental degradation in Niger. Mekonnen et al. (2015), in their analysis, show that fuelwood scarcity has a negative impact on time spent on agriculture; however, scarcity of water had no effect on time spent on agriculture in Ethiopia. Likewise, Mekonnen et al. (2017) on their analysis indicated that agricultural productivity decreases with increasing time spent on collecting animal dung but increases with time spent on collecting crop residue. The paper by Boone et al. (2011) suggests that long distance to water source increase water gathering time in Madagascar.

In spite of the recognized contributions of the existing studies, none of the above studies examine the effect of grazing and water on welfare and food security (Tangka and Jabbar, 2005; Cooke et al. 2008). Therefore, this study makes a noteworthy contribution in pointing out the relevance of improving feed and water management for the animal.

\section{Theoretical model}

The contribution of livestock to food and nutritional security in developing countries is significant (Swanepoel et al. 2010). In a mixed crop-livestock, Ethiopia owns a significantly large livestock population and its production mainly depends on natural resources such as grazing land, water, and own crop residue (Bezabih and Berhane 2014). Ethiopian farmers usually experience a very serious seasonal fluctuation in fodder and water availability for the animal. The dependence on these resources implies that scarcity can have a huge impact on household welfare (Bewket 2011; Bezabih and Berhane 2014). In rural farm households, where the farmer is engaged in both crop and livestock production activities, total time endowment is divided into three main activities: farm activities, off-farm activities, and leisure. However, considering the scarcity of these resources, the total time endowment will further include the 4th, collecting scarce resource activities.

We start with the downward spiral hypothesis which states that people in poverty are forced to deplete resources to survive, and this environmental depletion further 
impoverishes them (Ostrom et al. 1999). It is supposed that the scarcity of resource can affect household well-being either by affecting livestock production directly, affecting crop and off-farm income (via labor reallocation), or through its direct impact on time for food preparation or leisure consumption (Cooke et al. 2008; Mekonnen et al. 2015). To conceptualize the effect of resource scarcity on welfare and food security, we develop a theoretical model within the framework of household utility model following the work of Strauss (1986a) and later used by Faridi and Wadood (2010). We suppose that rural households are characterized as both producers and consumers of their food, and thus, household strictly quasi-concave utility function based on the framework of consumer demand and production theories is presented as follows:

$$
U_{i}=U\left(C_{i}, C_{n}, C_{m}, L_{l} ; \Gamma\right)
$$

where $U_{i}$ is a utility function that is twice differentiable, increasing in its arguments, and strictly quasi-concave; $C_{i}$ and $C_{n}$ are a vector of home produced food and non-food goods consumed by the $i$ th household; $C_{m}$ is a market-purchased goods consumed; and $L_{l}$ is leisure and $\Gamma$ is the vector of household sociodemographic variables. $C_{n}$ in this case represents the demand for non-food items such as education, health, and housing. Equation (1) leads us to the generalized utility function developed by Becker's (1981), which requires that production decision is first made to maximize profit and household maximizes utility using this maximum profit consecutively (Strauss 1986a). The meal production is a function of agricultural goods $\left(Q_{i}\right)$, off-farm income $(E)$, and fuel sources such as straw or dung $\left(E_{f}\right)$ as well as labor days the household spend on searching grazing land, water, and crop residue $\left(L_{c}\right)$. The production of household goods is also influenced by the vector of household characteristics.

$$
C_{i}=C\left(E_{f}, Q_{i}, \mathrm{E}, L_{c} ; \bigotimes\right)
$$

The rural household is assumed to maximize its utility subject to farm production, income, and time constraints specified as:

$$
F\left(Q_{i}, L, L_{c}, K, A\right)=0
$$

Equation (3) is a typical household implicit production function for food, $Q_{i}$ produced at home and assumed to be twice differentiable, increasing in outputs, decreasing in inputs, and strictly convex; $L$ is total labor used on the farm; $L_{c}$ is the time spent on searching grazing, water, and collecting crop residue; $K$ is the fixed capital stock and A is the farm size and the labor time is an important resource, denoted by $T$, and it is allocated among crop farming activities $L_{a}$, searching and collecting scarce resource $L_{c}$ and leisure $L_{l}$ :

$$
T=L_{a}+L_{c}+L_{l}
$$

At the same time, the income constraint for the rural household is given by

$$
P_{i}\left(Q_{i}-C_{i}\right)-P_{n} C_{n}-P_{m} C_{m}-W\left(L-L_{a}\right)+E=0
$$

$P_{i}$ is price of price of food produced, $P_{i} C_{i}$ is a marketed surplus of produced good, $P_{n}$ is the price of non-food goods, $P_{m}$ is the price of a market-purchased good, $W$ is the 
wage rate, $L_{a}$ is total family labor supply for on-farm use, and $E$ is non-farm income which adjusts to ensure that Eq. (5) equals zero. Substituting the right-hand side (RHS) of Eq. (4) into 5 yields:

$$
P_{i}\left(Q_{i}-C_{i}\right)-P_{n} C_{n}-P_{m} C_{m}-W\left(L-\mathrm{T}+L_{c}+L_{l}\right)+E=0
$$

Expanding and rearranging Eq. (6) produces an explicit household income and expenditure:

$$
P_{i} Q_{i}+W \mathrm{~T}+E-W L-W L c=P_{i} C_{i}+P_{n} C_{n}+P_{m} C_{m}+W L_{l}
$$

The left-hand side of Eq. (7) represents household's full income, which comprises of the value of farm produce $P_{i} Q$, the value of time endowment $W \mathrm{~T}$, non-farm income $E$, the value of labor used for farming including the hired labor $W L$, and value of labor spent for searching and collecting scarce resources $W L_{c}$. Similarly, the right-hand side of Eq. (7) is the household expenditure on food and leisure. The expenditure side includes purchases of its own produce food consumed $P_{i} C_{i}$, value of non-food expenditure $P_{n} C_{n}$, and value of market purchase food consumed $P_{m} C_{m}$ and purchase of leisure $W L_{l}$. The optimization of Eq. (1) yields income and expenditure equation within the separability assumption. At an interior solution, the household selects $L_{c}, L_{l}, \mathrm{~L}, C_{i}$, and $C_{m}$ to maximize Eq. (1) subject to Eqs. (7 and 3), which can be best visualized as:

$$
\begin{aligned}
\mathscr{L}= & U\left(C\left(E_{f}, Q_{i}, E, L_{c} ; \phi\right), C_{n}, C_{m}, L_{l} ; \Gamma\right) \\
& +\lambda\left(P_{i} Q_{i}+W \mathrm{~T}+E-W L-W L_{c}\right)-\left(P_{i} C_{i}+P_{n} C_{n}+P_{m} C_{m}+W L_{l}\right) \\
& +\gamma\left[F\left(Q_{i}, L, L_{c}, K, A\right)\right]
\end{aligned}
$$

Based on Strauss J (1983), it is possible via optimization of Eq. (8) yield production and consumption equations separately as discussed below. The first-order conditions are as follows:

$$
\begin{aligned}
& \frac{d \mathcal{L}}{d L_{c}}=\frac{d U}{d C} \frac{d C}{d L_{c}}-\lambda W+\gamma \frac{d F}{d L_{c}}=0 \\
& \frac{d \mathcal{L}}{d L_{l}}=\frac{d U}{d L_{l}}-\lambda W=0 \\
& \frac{d \mathcal{L}}{d L}=\gamma \frac{d F}{d L}-\lambda W=0 \\
& \frac{d \mathcal{L}}{d C_{i}}=\frac{\partial U}{\partial C_{i}}-\lambda P_{i}=0 \\
& \frac{d \mathscr{L}}{d C_{m}}=\frac{\partial U}{\partial C_{m}}-\lambda P_{m}=0 \\
& \frac{d \mathscr{L}}{d C_{n}}=\frac{\partial U}{\partial C_{n}}-\lambda P_{n}=0
\end{aligned}
$$

Maximizing the first-order condition of the LHS of Eq. (8) with respect to labor $\left(L^{*}\right)$ and output produced $\left(Q^{*}\right)$, the demand for inputs and output is derived in terms of all prices, the wage rate, time for searching and collecting scarce resource, fixed land, and capital as:

$$
L^{*}=l^{*}\left(P_{i}, P_{m}, P_{n}, W, L_{c}, K, A\right)
$$




$$
Q^{*}=Q^{*}\left(P_{i}, P_{m}, P_{n}, W, L_{c}, K, A\right)
$$

Substituting optimal labor, $L^{*}$ and optimum output $Q^{*}$ into LHS of Eq. (7) produces optimum income/full income $Y^{*}$ under the assumption of maximized profit $\pi^{*}$ as:

$$
\begin{aligned}
& Y^{*}=P_{i} Q^{*}+W \mathrm{~T}+E-W L^{*}-W L_{c} \\
& Y^{*}=W \mathrm{~T}+\pi^{*}\left(P_{i}, P_{m}, P_{n}, W, L_{c}, K, A\right)+E
\end{aligned}
$$

where $\pi^{\prime \prime}\left(P_{i}, P_{m}, P_{n}, W, L_{c}, K, A\right)$ represents $P_{i} Q^{\prime \prime}-W L^{*}-W L_{c}$

The first-order conditions of the RHS of Eq. (7) gives consumption demand function in terms of prices, the wage rate, and income and household's preferences represented by household demographic characteristics $\Gamma$. This relationship can be specified as:

$$
C_{d}=c\left(P_{i}, P_{m}, P_{n}, W, L_{c}, Y^{*}\left(P_{i}, P_{m}, P_{n}, W, L_{c}, K, A, E\right) ; \Gamma\right)
$$

The above equation states that household food consumption $C_{d}$ is mainly influenced by both food and non-food prices, wages, resource scarcity, and household income. Referring that household demand for food as a measure of household food security (FS), then $C_{d}$ is a reduced form of the utility function in Eq. (1), which allows the evaluation of the effects of demographic and economic variables. Food security is approximated by food consumption expenditure ${ }^{3}$ in this case.

The effect of scarce resource on agricultural production is investigated through the production sector and its direct impact on household's utility is explored through consumption sector. Thus, the total effect which is the sum of the two effects can be further explained using Eq. (11). Since time spent for searching grazing or water and collecting straw is one explanatory variable of agricultural output function, the total effect of this variable on per capita food expenditure is:

$$
\frac{d C_{d}}{d L_{c}}=\frac{d C_{d}}{d Y} \frac{d Y}{d L_{c}}+\frac{d C_{d}}{d L_{c}}
$$

Then, the total effect is simply calculated by taking the slope coefficient of income in the consumption regression multiplied by the coefficient of time allocation in the production estimation, plus the coefficient of time allocation in the consumption regression.

\section{Materials and methods}

\section{Study area and dataset}

Ethiopia is a federal country divided into 9 regions and 2 administrative cities. Each region is subdivided into zones and zones into woredas. Woredas, in turn, are divided into peasant Associations (PA) or Tabias, an administrative unit consisting of a number of smallest villages and individual households. The study consisted of 21 Tabias stratified by agroecology and socio-economic indicators to get variations in population density and market access during the initial baseline. The main criteria used for stratification and sampling include ecology excluding lowlands $(<1500$ m.a.s.l.), geographical zone (Eastern, Southern, Southeastern, Central, and Western) to reflect variations in rainfall and development pathways, distance to market based on far (>10 km) versus near $(<10 \mathrm{~km})$, population density, and irrigation access. 
Initially, to reflect systematic variation in agro-climatic conditions, agricultural potential, population density, and market access conditions, four communities were selected from each of the four zones and three communities that represent irrigation projects. Likewise, one with low population density and one with high population density were strategically selected from each zone among communities to reflect far distance market (Hagos 2003). The initial data collection was carried out for a random sample of 400 households in 16 villages from the specified four zones of the region (Hagos 2003). This study is conducted in Tigrai region, the northern part of Ethiopia by randomly selecting 632 sample households from 21 villages. This is because the original data set was collected by Ph.D. students of the Norwegian University of Life Science, who originally came from Tigrai region. An extra 5 villages and 232 households were included to the original sample size for the simple reason that this study was conducted mainly to evaluate the impact of land certification, and thus, more control groups were required.

The data includes a panel of five rounds conducted in 1997/1998, 2000/2001, 2002/ 2003, 2005/2006, and 2014/2015 where the author is involved only in collecting the data for the last round. The available panel dataset provides comprehensive household and plot level data on household characteristics, agriculture and livestock information, food consumption, rental market participation, land certificate perception, and community-level data on GPS information including rainfall, total cultivated, irrigated and grazing area, wages, and conservation activities under safety net activities This study used cross-sectional data from NMBU-MU ${ }^{4}$ Tigrai Rural Household Survey dataset collected in 2015. The primary data used in this paper is adapted from the last, 2014/2015, household survey. The need for information regarding livestock activity reduced further our sample size from 632 to 518 only livestock owner-farmers for this study.

\section{Econometric model specification}

In order to estimate welfare, we are forced to approximate by per capita food consumption expenditure (PCFE) due to limited data. ${ }^{5}$ Assuming that the demand equation from the utility maximization of the recursive household model has a functional form of log-linear, its capability of estimating respective elasticities as its coefficient and modeling nonlinear effects makes it applicable and preferable (Oum 1989). Oum added that the log-linear demand function resembles the demand function obtainable from a Cobb-Douglas utility function with the drawback of invariant estimated elasticities across all data points. The aggregate demand equation per household is estimated for PCFE rather than estimating single demand equations for each product consumed or for each individual member of the household. Following Adewuyi et al. (2009); Badalona and Isitor (2014), the implicit form of the OLS is given as:

$$
\ln C_{d}=\delta+\delta Y_{i}+\sum_{k=1}^{K} \beta_{k} \ln X_{i}+v
$$

where $\ln C_{d}$ is households' PCFE; $Y_{i}$ is rural farm and off-farm income; $X_{i}$ for $k=1 \ldots K$, includes consumption side variables and household characteristics; $X_{1}$ is aggregate monetary value of crop production; $X_{2}$ is herd size in tropical livestock unit; $X_{3}$ is family size; $X_{4}$ is gender of the household head with male being equal to $1 ; X_{5}$ refers to the access of information via radio, TV, and mobile in binary form; $X_{6}$ reflects the agro 
ecological location of each household measured by GPS but classified as highland if it is 2500 m.a.s.l. and lowland if it is below that; $X_{7}$ represents market distance in minutes; $X_{8}$ and $X_{9}$ correspond to the dummy exposure of animal shock in 2013 and cumulative number of shocks from 2012 to 2014; $X_{10}=1$ if the household is reported to be orthodox; $X_{11}=1$ if the household gets assistance from relatives and friends while $X_{12}$ and $X_{13}$ capture the age of house head in years and total farm income composed of farm income, off-farm income, business transfer, and safety net income. The resource scarcity is captured by the walking distance to the water source in minutes/day/trip $\left(X_{14}\right)$, walking distance to the grazing source in minutes/day/trip $\left(X_{15}\right)$ and walking distance to the crop residue site in minutes/trip $\left(X_{16}\right)$ per year.

$v$ is an error term. Since farm and off-farm income is not randomly distributed among rural households, this variable is likely to be endogenous (Hoddinott et al. 2008), which could be caused by omitted variables, measurement error, simultaneity, or household unobservable. First, a reverse causality problem might exist, because PCFE at the household level might also influence labor productivity and thus farm productivity. Second, farm and off-farm income might be influenced by household unobservable, which can lead to correlation with the error term. In the presence of endogeneity, the use of the OLS estimator biases the effect of income (Wooldridge 2009).

In order to avoid an endogeneity bias, I adopted a two-stage least square (2SLS) approach which is the most common instrumental variable estimator (Angrist and Evans 1998) where rural farm income is instrumented by shock exposure and average rainfall of 2003-2014. This is similar to approaches that have been used by Sarris et al. (2006), Hidalgo et al. (2010), and (Abdulai and Huffman 2014) in different contexts. A shock caused by crop theft, illness, and death of a household member is expected to affect income and output negatively, thereby reducing food expenditure (Abdulai and Huffman 2014; Dercon et al. 2005).

The explanation is that farm income is to decrease with increasing any shock on crop or animal farming caused by a theft or illness of the household. Then, its effect on consumption reaches through its effect on farm income. Our justification for using rainfall is that average shortfall of rainfall influence rural farm income without directly influencing the consumption expenditure in the village. Increasing rainfall is expected to increase farm income directly but consumption indirectly through its effect on income (Hidalgo et al. 2010). With this procedure, the structural equation is specified as

$$
\ln C_{d}=\delta+\delta^{i v} \hat{Y}++\sum_{k=1}^{K} \beta_{k} \ln X_{i}+\varepsilon
$$

where $\ln C_{d}$ is PCFE, $\hat{Y}$ is predicted values of the endogenous rural income variable, and $\varepsilon$ is an error term, $\beta$ is parameter coefficient of the vectors of an exogenous variable, $X$. To obtain income $(Y)$, the first stage regression equation is estimated by OLS based on the following specifications:

$$
\ln Y=\alpha+Z^{\prime} \gamma+X^{\prime} \beta+\epsilon
$$

where, $\ln Y$ is the total rural income of the household, $\gamma$ is the parameter coefficients of the vector of the instrumental variables, $Z$ which is assumed to correlate with income $(Y)$ but not with the error term, $\varepsilon$ in the structural Eq. (14). The estimated PCFE of the household, in (14) is now assumed to be unbiased. In order to estimate the effects of 
water and feed scarcity across the entire distribution of the dependent variables, PCFE, and to document the heterogeneity in the way food consumption respond to these scarcity variations, an alternative quantile regression was used following Koenker and Bassett (1978) estimation approach.

\section{Results and discussions}

\section{Descriptive statistics}

Table 1 presents the summary of basic variables of 518 farm households drawn from a total of 632 sample farmers. On the welfare side, the dependent variable is per capita food consumption expenditure (PCFE). ${ }^{6}$ For each household, expenditure profile on the following seven food groups was recorded: (1) staple foods including cereals and pulses; (2) meat, egg, and fish; (3) dairy products; (4) fruits and vegetables; (5) fats and oils; (6) sugar and honey; and (7) miscellaneous such as tea and coffee. Likewise, the

Table 1 Descriptive and summary statistics

\begin{tabular}{|c|c|c|c|}
\hline \multirow[t]{2}{*}{ Variables } & \multicolumn{3}{|l|}{$N=518$} \\
\hline & Description & Mean & SD \\
\hline \multicolumn{4}{|l|}{ Dependent variables } \\
\hline $\mathrm{FE}$ & Monetary value of food expenditure in ETB ${ }^{a}$ & $13,571.4$ & $19,717.4$ \\
\hline PCFE & Monetary value of per capita food expenditure in ETB & 2490 & 3722 \\
\hline Output & Monetary value of crop production ${ }^{\mathrm{b}}$ in ETB & 41,645 & 87,517 \\
\hline $\mathrm{Fl}$ & Food Security Index ${ }^{c}$ & 0.4826 & 0.5001 \\
\hline \multicolumn{4}{|l|}{ Independent variables } \\
\hline ShadowPW & Shadow price of water & 147.6 & 204.9 \\
\hline ShadowPG & Shadow price of grazing & 205.0 & 282.0 \\
\hline ShadowPF & Shadow price of crop residue & 12.52 & 18.96 \\
\hline WaterD & Distance to animal water source in walking minute & 74.85 & 65.54 \\
\hline GrazingD & Time spent looking for grazing land in walking minute & 91.12 & 83.44 \\
\hline FeedD & Time to transport crop reside in walking minute & 576.55 & 557.87 \\
\hline Income & Monetary value of total income ${ }^{d}$ & 49,521 & 92,642 \\
\hline Family size & Household family size & 5.873 & 2.413 \\
\hline Age & Household head age & 56.83 & 15.20 \\
\hline Gender & $1=$ male & 0.743 & 0.437 \\
\hline Education & $1=$ literate & 0.326 & 0.469 \\
\hline TLU & Herd size in TLU & 3.919 & 3.199 \\
\hline MarketD & Market distance in minute & 82.30 & 54.79 \\
\hline Shocks (2012-2014) & Number of shocks due to theft, flood, death & 0.577 & 0.826 \\
\hline Information & $1=$ access to $T \mathrm{~V}$, radio, and mobile & 0.417 & 0.494 \\
\hline Location & $1=$ highland (> 2500 m.a.s.l.) & 0.0637 & 0.244 \\
\hline Network & $1=$ support from relatives and friends & 0.610 & 0.488 \\
\hline Religion & $1=$ orthodox and 0 Muslim & 0.824 & 0.381 \\
\hline Ashock13 & $1=$ face animal shock in 2013 & 0.0425 & 0.202 \\
\hline
\end{tabular}

${ }^{a}$ ETB refers to Ethiopian currency where 1 USD $\approx 23$ ETB during the study year (2015)

${ }^{\mathrm{b}}$ It includes crop, fruit, and vegetable production

${ }^{\mathrm{C}} \mathrm{A}$ household is considered food secure if it attains at least two thirds of the average PCFE of all households and considered food insecure if it falls below that value

${ }^{d}$ It includes income from Agriculture, off-farm, business transfer, and safety net 
dependent variable on the production side is an aggregate monetary value of all crops produced during the survey production season.

An average household has produced an average agricultural output of worth 41,645 ETB and the average total income including sales from agricultural output worth 49,426 ETB. Households, on average, spend approximately about 13,571 ETB for food with average PCFE of 2490 ETB in the year. We also construct the food security-dependent variable by classifying households into food secure and food insecure using food security index calculated by dividing the individual PCFE to two-third average PCFE of all households. ${ }^{7}$ Accordingly, a household is considered food secure if it attains at least two thirds of the average per capita food expenditure of all households and considered food insecure if it falls below that value.

The results in Table 1 showed that $48 \%$ of the households were food secure while $52 \%$ were food insecure given the two thirds of the average of all households is 1660 ETB. Feleke et al. (2005) documented about 40\% incidence of food insecurity in Ethiopia. Regarding the scarcity indicator, we know that grazing land and water resources are challenging to value because they are not traded and have no market price. Their prices are a shadow price (Magnan et al. 2012) since shadow prices are assumed to reflect better the economic scarcity of environmental goods to a household (Cooke 1998). For this reason, as a proxy indicator for scarcity, first, we use walking distance for a single trip to measure grazing, water, and crop residue using similar approach used by Palmer and MacGregor (2009). On average, the households spend $1.25 \mathrm{~h} /$ day to reach a water source for animal and $1.5 \mathrm{~h}$ /day to search for communal grazing land, maximum time reaching up to $6 \mathrm{~h}$ for water site and $8 \mathrm{~h}$ for grazing land in the data. Besides, the average time spent on collecting crop residue by the household is $9.6 \mathrm{~h}$ per a single trip on foot.

Second, following Baland et al. (2010), Cooke (1998), and Mekonnen et al. (2015), we measure the shadow price of searching grazing and water as well as collecting crop residue for animal as the time taken to search grazing land and water per animal or to collect crop residue per its amount collected multiplied by the village median adjusted ${ }^{8}$ off-farm wage. Cooke (1998) and Mekonnen et al. (2015) use shadow price of fuelwood, leaf fodder, water, and grass to measure scarcity. In this paper, we take the wage rate at the village level, and thus, there is no variation in wages for households living in the same village. In this way, we produce a household specific shadow price of searching grazing land or water and collecting straw. Table 1 reported that the average shadow price for animal watering is about 147 ETB per day which is equivalent to the average daily rural wage rate in the region. On average, the opportunity cost of searching grazing is 205 ETB per day, which is greater than the opportunity cost of water and straw. This is not surprising, as rural farmers usually spend a huge amount of time in searching grazing than watering. As expected, the shadow price of collecting a residual crop is 12 ETB per trip.

Out of the total sample, $6.4 \%$ lives in highland parts of the region. Nearly $39 \%$ of the households report that they have been severely affected by 11 different level of shocks including, drought, pests, flood, theft, illness and death, loss of job, and home damage in the last harvesting years with a mean of 0.57 shock occurrence and $4.25 \%$ of households report having been affected by animal shocks 1 year before the harvesting season. Seventy-four percent of the households are male heads with an average age of 57 years 
and family size of 5.87. Since resources are very scarce, high family size may put much more pressure on consumption than it contributes to production.

Nearly $32 \%$ of the household heads have at least one or more years of education. Thus, it is hypothesized that education is negatively related to consumption value.

Around $82 \%$ of the households are Orthodox followers while $18 \%$ of the households are Muslim households in the study area. Out of the 518 households in the sample, $61 \%$ got assistance either from their relatives or friends and is expected to increase production and consumption (Di Falco et al. 2011). More than 40\% of household heads site attend media via TV, radio, and mobile phone about any development intervention. Hence, it is expected that households with information are more likely to produce more and be food secure. The expected effect on production and consumption is positive ( $\mathrm{Di}$ Falco et al. 2011). In addition, the average livestock endowment of the sample households is 4 Tropical Livestock Unit (TLU) which expected to increase food security and food consumption. Physical access to the market is measured by the amount of time required to get to the nearest local market and its mean values is reported to be $82 \mathrm{~min}$. Thus, its expected effect on consumption is negative, indicating that longer distance leads to less frequency of visit and hence less likely to get market information about selling and buying prices (Feleke et al. 2005).

\section{Econometric model results}

The PCFE is analyzed using the demand functions derived from maximized utility subject to budget constraint and technology constraint of farm production, and its estimated result is presented in Tables 3 and 4 where walking distance and shadow prices are used as scarcity indicators using naive OLS and IV methods. In the IV 2SLS, total rural income is instrumented by shock exposure and average rainfall of 2003-2014. Tables 3 and 4 compare results from naive OLS and 2SLS estimates for all variables of interest, namely water, grazing land, and crop residue distance. The potential candidate instruments used in the estimation were tested to check if they could pass the necessary requirements for an instrument to be as an instrument.

Table 2 reports test results for all scenarios presented in Tables 3 and 4 . The Wu-Hausman $F$ test with a $P$ value less than 0.05 rejected the null hypothesis that OLS estimation is consistent or income is exogenous and motivates the use of instruments. Besides, the Sargan chi-squared test fails to reject the null hypothesis that all instruments are uncorrelated with the error term in the structural model or all instruments are valid and this helps to conclude that the instruments pass the over-identification requirement for all estimates. Finally, instruments were also tested if they could pass the second most important criteria that the instrument should be correlated or relevant to

Table 2 Instrumental variables tests

\begin{tabular}{llll}
\hline Estimates & Endogeneity & Validity & Relevance \\
\hline & Criteria & & \\
& Wu-Hausman $(P$ value) & Sargan $(P$ value) & Stock and Yogo, F value \\
Water scarcity model & $(0.0008)$ & $(0.5562)$ & 42.28 \\
Gazing scarcity model & $(0.0011)$ & $(0.5236)$ & 42.27 \\
Straw scarcity model & $(0.0013)$ & $(0.5417)$ & 42.56 \\
\hline
\end{tabular}


Table 3 IV estimation of log per capita food expenditure using walking distance

\begin{tabular}{|c|c|c|c|c|c|c|}
\hline \multirow[t]{2}{*}{ Variables } & (OLS) & (IV) & (OLS) & (IV) & (OLS) & (IV) \\
\hline & InPCFE & InPCFE & InPCFE & InPCFE & InPCFE & InPCFE \\
\hline \multirow[t]{2}{*}{ Ln(output) } & $0.0940^{* * *}$ & $0.0629^{* * *}$ & $0.0909^{* * *}$ & $0.0631^{* * *}$ & $0.0986^{* * *}$ & $0.0685^{* * *}$ \\
\hline & $(0.0121)$ & $(0.0164)$ & $(0.0125)$ & $(0.0164)$ & $(0.0122)$ & $(0.0164)$ \\
\hline \multirow[t]{2}{*}{ Ln(livestock) } & $0.0336^{* * *}$ & $0.0287^{* *}$ & $0.0334^{* *}$ & $0.0298^{* *}$ & $0.0352^{* * *}$ & $0.0305^{* *}$ \\
\hline & $(0.0129)$ & $(0.0134)$ & $(0.0131)$ & $(0.0134)$ & $(0.0130)$ & $(0.0135)$ \\
\hline \multirow[t]{2}{*}{ Ln(Family size) } & $-0.385^{* * *}$ & $-0.362^{* * *}$ & $-0.397^{* * *}$ & $-0.374^{* * *}$ & $-0.388^{* * *}$ & $-0.366^{* * *}$ \\
\hline & $(0.0529)$ & $(0.0551)$ & $(0.0535)$ & $(0.0554)$ & $(0.0534)$ & $(0.0554)$ \\
\hline \multirow[t]{2}{*}{ Gender(1/0) } & $-0.119^{* *}$ & $-0.136^{* *}$ & $-0.0993^{*}$ & $-0.114^{*}$ & $-0.115^{*}$ & $-0.133^{* *}$ \\
\hline & $(0.0588)$ & $(0.0608)$ & $(0.0590)$ & $(0.0607)$ & $(0.0593)$ & $(0.0613)$ \\
\hline \multirow[t]{2}{*}{ Information(1/0) } & 0.0591 & 0.0409 & 0.0454 & 0.0288 & 0.0487 & 0.0299 \\
\hline & $(0.0539)$ & $(0.0558)$ & $(0.0545)$ & $(0.0562)$ & $(0.0544)$ & $(0.0563)$ \\
\hline \multirow[t]{2}{*}{ Location(1/0) } & -0.0411 & -0.0519 & -0.114 & -0.129 & -0.149 & -0.169 \\
\hline & $(0.140)$ & $(0.144)$ & $(0.140)$ & $(0.143)$ & $(0.141)$ & $(0.145)$ \\
\hline \multirow[t]{2}{*}{ Ln(marketD) } & 0.00283 & 0.0166 & 0.00252 & 0.0165 & 0.00144 & 0.0146 \\
\hline & $(0.0337)$ & $(0.0350)$ & $(0.0340)$ & $(0.0353)$ & $(0.0340)$ & $(0.0353)$ \\
\hline \multirow[t]{2}{*}{ Ashock13(1/0) } & $-0.489^{* *}$ & $-0.399^{* *}$ & $-0.550^{* * *}$ & $-0.463^{* *}$ & $-0.540^{* * *}$ & $-0.457^{* *}$ \\
\hline & $(0.191)$ & $(0.199)$ & $(0.192)$ & $(0.200)$ & $(0.193)$ & $(0.200)$ \\
\hline \multirow[t]{2}{*}{ Ln(shocks) } & 0.212 & $0.345^{*}$ & 0.307 & $0.434^{* *}$ & 0.267 & $0.401^{*}$ \\
\hline & $(0.198)$ & $(0.209)$ & (0.199) & $(0.210)$ & $(0.200)$ & $(0.210)$ \\
\hline \multirow[t]{2}{*}{ Religion(1/0) } & $0.121^{*}$ & $0.146^{* *}$ & 0.101 & $0.124^{*}$ & 0.115 & $0.140^{*}$ \\
\hline & $(0.0700)$ & $(0.0726)$ & $(0.0705)$ & $(0.0727)$ & $(0.0706)$ & $(0.0730)$ \\
\hline \multirow[t]{2}{*}{ Network(1/0) } & -0.0833 & $-0.172^{* * *}$ & -0.0761 & $-0.158^{* *}$ & -0.0729 & $-0.159^{* *}$ \\
\hline & $(0.0554)$ & $(0.0647)$ & $(0.0559)$ & $(0.0647)$ & $(0.0558)$ & $(0.0649)$ \\
\hline \multirow[t]{2}{*}{ Age(years) } & -0.000477 & -0.000749 & -0.000535 & -0.000786 & -0.000554 & -0.000829 \\
\hline & $(0.00174)$ & $(0.00179)$ & $(0.00175)$ & $(0.00180)$ & $(0.00175)$ & $(0.00180)$ \\
\hline \multirow[t]{2}{*}{ Ln(income) } & $0.0440^{* * *}$ & $0.0565^{* * *}$ & $0.0433^{* * *}$ & $0.0552^{* * *}$ & $0.0439^{* * *}$ & $0.0562^{* * *}$ \\
\hline & $(0.00187)$ & $(0.00473)$ & (0.00189) & $(0.00476)$ & $(0.00189)$ & $(0.00475)$ \\
\hline \multirow[t]{2}{*}{ Ln(WaterD) } & $-0.122^{* * *}$ & $-0.131^{* * *}$ & & & & \\
\hline & $(0.0309)$ & $(0.0320)$ & & & & \\
\hline \multirow[t]{2}{*}{ Ln(GrazingD) } & & & $-0.100^{* * *}$ & $-0.0888^{* *}$ & & \\
\hline & & & $(0.0336)$ & $(0.0347)$ & & \\
\hline \multirow[t]{2}{*}{ Ln(FeedD) } & & & & & $-0.0642^{* * *}$ & $-0.0716^{* * *}$ \\
\hline & & & & & $(0.0240)$ & $(0.0248)$ \\
\hline \multirow[t]{2}{*}{ Constant } & $6.018^{* * *}$ & $5.970^{* * *}$ & $6.046^{* * *}$ & $5.898^{* * *}$ & $5.917^{* * *}$ & $5.880^{* * *}$ \\
\hline & $(0.291)$ & $(0.300)$ & $(0.318)$ & $(0.330)$ & $(0.305)$ & $(0.319)$ \\
\hline R-squared & 0.710 & 0.683 & 0.705 & 0.681 & 0.705 & 0.679 \\
\hline \multicolumn{7}{|l|}{ First stage } \\
\hline \multirow[t]{2}{*}{ Shock } & & $-20.132^{* * *}$ & & $-20.122^{* * *}$ & & $-20.140^{* * *}$ \\
\hline & & $(2.1697)$ & & (2.1718) & & (2.1686) \\
\hline \multirow[t]{2}{*}{ Rainfall } & & $0.1655^{* *}$ & & $0.1612^{* *}$ & & $0.1657^{* *}$ \\
\hline & & $(0.0573)$ & & $(0.0577)$ & & $(0.0572)$ \\
\hline Observation & 496 & 496 & 496 & 496 & 496 & 496 \\
\hline
\end{tabular}

$P$ values are for slopes: ${ }^{* *} P<0.01 ;{ }^{*} P<0.05$, and ${ }^{*} P<0.10=$ significant at $1 \%, 5 \%$, and $10 \%$ probability levels, respectively 
Table 4 IV estimation of log per capita food expenditure using shadow prices

\begin{tabular}{|c|c|c|c|c|c|c|}
\hline \multirow[t]{2}{*}{ Variables } & (OLS) & (IV) & (OLS) & (IV) & (OLS) & (IV) \\
\hline & InPCFE & InPCFE & InPCFE & InPCFE & InPCFE & InPCFE \\
\hline \multirow[t]{2}{*}{ Ln(output) } & $0.0998^{* * *}$ & $0.0698^{* * *}$ & $0.0984^{* * *}$ & $0.0677^{* * *}$ & $0.0842^{* * *}$ & $0.0587^{* * * *}$ \\
\hline & $(0.0122)$ & $(0.0164)$ & $(0.0123)$ & $(0.0164)$ & $(0.0131)$ & $(0.0165)$ \\
\hline \multirow[t]{2}{*}{ Ln(livestock) } & $0.0381^{* * *}$ & $0.0337^{* *}$ & $0.0368^{* * *}$ & $0.0330^{* *}$ & $0.0363^{* * *}$ & $0.0327^{* *}$ \\
\hline & $(0.0130)$ & $(0.0134)$ & $(0.0130)$ & $(0.0135)$ & $(0.0129)$ & $(0.0133)$ \\
\hline \multirow[t]{2}{*}{ Ln(Family size) } & $-0.388^{* * *}$ & $-0.366^{* * *}$ & $-0.380^{* * *}$ & $-0.356^{* * *}$ & $-0.379^{* * *}$ & $-0.360^{* * *}$ \\
\hline & $(0.0536)$ & $(0.0556)$ & $(0.0538)$ & $(0.0562)$ & $(0.0533)$ & $(0.0550)$ \\
\hline \multirow[t]{2}{*}{ Gender(1/0) } & $-0.103^{*}$ & $-0.118^{*}$ & -0.0846 & $-0.105^{*}$ & $-0.113^{*}$ & $-0.125^{* *}$ \\
\hline & $(0.0593)$ & $(0.0612)$ & $(0.0595)$ & $(0.0618)$ & $(0.0591)$ & $(0.0605)$ \\
\hline \multirow[t]{2}{*}{ Information(1/0) } & 0.0544 & 0.0363 & 0.0401 & 0.0250 & 0.0412 & 0.0267 \\
\hline & $(0.0546)$ & $(0.0564)$ & $(0.0546)$ & $(0.0567)$ & $(0.0544)$ & $(0.0559)$ \\
\hline \multirow[t]{2}{*}{ Location(1/0) } & -0.0480 & -0.0629 & -0.0567 & -0.0910 & -0.126 & -0.139 \\
\hline & $(0.145)$ & $(0.149)$ & $(0.141)$ & $(0.146)$ & $(0.140)$ & $(0.143)$ \\
\hline \multirow[t]{2}{*}{ Ln(MarketD) } & 0.00360 & 0.0173 & 0.000178 & 0.0150 & 0.00219 & 0.0157 \\
\hline & $(0.0341)$ & $(0.0354)$ & $(0.0342)$ & $(0.0357)$ & $(0.0339)$ & $(0.0350)$ \\
\hline \multirow[t]{2}{*}{ Ashock13(1/0) } & $-0.494^{* *}$ & $-0.408^{* *}$ & $-0.526^{* * *}$ & $-0.431^{* *}$ & $-0.505^{* * *}$ & $-0.426^{* *}$ \\
\hline & $(0.193)$ & $(0.201)$ & $(0.192)$ & $(0.201)$ & $(0.192)$ & $(0.198)$ \\
\hline \multirow[t]{2}{*}{ Ln(Shocks) } & 0.220 & $0.354^{*}$ & 0.241 & $0.396^{*}$ & 0.247 & $0.378^{*}$ \\
\hline & $(0.203)$ & $(0.214)$ & $(0.199)$ & $(0.212)$ & $(0.199)$ & $(0.210)$ \\
\hline \multirow[t]{2}{*}{ Religion(1/0) } & $0.119^{*}$ & $0.143^{*}$ & 0.0948 & $0.122^{*}$ & 0.111 & $0.132^{*}$ \\
\hline & $(0.0712)$ & $(0.0736)$ & $(0.0707)$ & $(0.0736)$ & $(0.0704)$ & $(0.0724)$ \\
\hline \multirow[t]{2}{*}{ Network(1/0) } & -0.0839 & $-0.170^{* * *}$ & -0.0833 & $-0.167^{* * *}$ & -0.0677 & $-0.147^{* *}$ \\
\hline & $(0.0567)$ & $(0.0657)$ & $(0.0564)$ & $(0.0646)$ & $(0.0557)$ & $(0.0645)$ \\
\hline \multirow[t]{2}{*}{ Age(years) } & -0.000615 & -0.000883 & -0.000760 & -0.000914 & -0.000504 & -0.000746 \\
\hline & $(0.00176)$ & $(0.00181)$ & $(0.00176)$ & $(0.00182)$ & $(0.00175)$ & $(0.00179)$ \\
\hline \multirow[t]{2}{*}{ Ln(Income) } & $0.0437^{* * *}$ & $0.0560^{* * *}$ & $0.0426^{* * *}$ & $0.0558^{* * *}$ & $0.0432^{* * *}$ & $0.0547^{* * *}$ \\
\hline & $(0.00189)$ & $(0.00476)$ & $(0.00190)$ & $(0.00482)$ & $(0.00189)$ & $(0.00478)$ \\
\hline \multirow[t]{2}{*}{ Ln(ShadowPW) } & $-0.0520^{*}$ & $-0.0528^{*}$ & & & & \\
\hline & $(0.0295)$ & $(0.0303)$ & & & & \\
\hline \multirow[t]{2}{*}{ Ln(ShadowPG) } & & & $-0.0972^{* * *}$ & $-0.0669^{* *}$ & & \\
\hline & & & $(0.0286)$ & $(0.0312)$ & & \\
\hline \multirow[t]{2}{*}{ Ln(ShadowPF) } & & & & & $-0.0525^{* * *}$ & $-0.0441^{* *}$ \\
\hline & & & & & $(0.0172)$ & $(0.0178)$ \\
\hline \multirow[t]{2}{*}{ Constant } & $5.753^{* * *}$ & $5.672^{* * *}$ & $6.052^{* * *}$ & $5.785^{* * *}$ & $5.835^{* * *}$ & $5.702^{* * *}$ \\
\hline & $(0.300)$ & $(0.309)$ & $(0.308)$ & $(0.331)$ & $(0.283)$ & $(0.294)$ \\
\hline R-squared & 0.702 & 0.676 & 0.705 & 0.675 & 0.706 & 0.684 \\
\hline \multicolumn{7}{|l|}{ First stage } \\
\hline \multirow[t]{2}{*}{ Average rainfall } & & $0.1665^{* * *}$ & & $0.1459^{* * *}$ & & $0.1629^{* * *}$ \\
\hline & & (0. .0573) & & (0. 0581) & & $(0.0574)$ \\
\hline \multirow[t]{2}{*}{ Shock } & & $-20.1556^{* * *}$ & & $-19.932^{* * *}$ & & $-20.004^{* * *}$ \\
\hline & & $(2.184)$ & & (2.1718) & & $(2.1765)$ \\
\hline Observation & 496 & 496 & 496 & 496 & 496 & 496 \\
\hline
\end{tabular}

$P$ values are for slopes: ${ }^{* *} P<0.01,{ }^{*} P<0.05$, and ${ }^{*} P<0.10=$ significant at $1 \%, 5 \%$, and $10 \%$, probability levels, respectively 
the endogenous variable income. To ensure the relevance of instruments, the Stock and Yogo (2005) $F$ test was employed and provides higher value $F$ statistics which is extremely higher than the rule of thumb of at least greater than 10 .

The first-stage regression results of two-stage least square (2SLS) which are not reported here show that both instruments have a statistical relationship with income and carry the expected sign in all scenarios (Tables 3 and 4). Household income is often a major determinant of expenditure (Babalola and Isitor 2014). Total income of the household, which has positive coefficient significantly affected PCFE. Column $(1,3$, and 5) of Table 3 shows the income effect by estimating the consumption model using OLS estimator. The coefficient of income suggests that a $1 \%$ increase in income increases PCFE by around $0.044 \%$, whereas the 2SLS result displays that a $1 \%$ increase in total income leads to $0.059 \%$ increase in PCFE in all estimates. Because, as the income level of the household increases, the household purchasing power increases.

It turns out that this naive ordinary estimate grossly underestimates the income effect compared to effects from the IV 2SLS estimate. This implies that estimating the model using OLS is not the correct approach and ignoring these differences would bias the income effect. The findings of Babalola and Isitor (2014), Njimanted (2006), and Thirumarpan (2013) also confirm that household income is one of the key determinants of food expenditure and food security in rural areas. We also report that farm output significantly affects household food consumption. The elasticity of PCFE with respect to the gross crop value is equal to $0.063 \%$ for IV in the water scarcity estimates. Similar effects are found in the grazing and feed estimates presented in Table 3 of columns 3 to 6 . This is in line with Sarris et al. (2006) who found that agricultural productivity significantly affects PCFE in Ethiopia. The coefficient's sign and statistical significance show that livestock ownership is positively correlated with PCFE, suggesting that farmers with high herd size have a higher food consumption expenditure. Studies by Dercon et al. (2005) in Ethiopia and Sarris et al. (2006) in Tanzania found a similar result.

Another significant variable is household size, leading to $0.363 \%$ decrease in PCFE for $1 \%$ increase in the number of member of the household. This result is in line with the findings of (Bezu et al. 2014; Dercon et al. 2005) in Ethiopia and Sarris et al. (2006) in Tanzania. A household with a male head has a disadvantage of 0.136\% decrement in PCFE against the findings of Dercon et al. (2005) in Ethiopia. Experiencing an animal shock at least once in the previous year lowers PCFE by $0.399 \%, 0.463 \%$, and $0.457 \%$ for the three cases taking the estimated value of IV in Table 3. In line to this, Dercon (2004) found that a livestock shock negatively affects PCFE in rural Ethiopia.

The coefficient of religion is $0.146 \%$ and is statistically significant, implying that orthodox households have $0.146 \%$ PCFE higher than Muslim group referring to the IV estimate which is opposite to the result of Oldiges (2012) in India. The negative and significant sign of network shows that individuals who got social supports have $0.172 \%$ less PCFE, implying that supports from relatives or friends are not adequate enough to cover food expenditure for the recipient households. A similar result was found by Sarris et al. (2006). Other insignificant variables are proximity to market (positive), information (positive), and the age of the household head (negative) in line with the study of Matchaya and Chilonda (2012) in Malawi. 
The main interest of this paper is to explore how time spent for animal feed and water searching directly affect PCFE and our result is in line with the downward spiral hypothesis (Ostrom et al. 1999). Using distance indicator in Table 3, time spent looking for water and grazing land has resulted in a negative sign and it is found to be an important factor of PCFE. A $1 \%$ increase in minutes traveled to reach water and grazing land leads to a $0.131 \%$ and $0.088 \%$ decrease in PCFE, respectively, using IV. In addition, a $1 \%$ increase in minutes traveled on foot to collect crop residue leads to $0.072 \%$ decrease in PCFE. Likewise, our results from the shadow price (Table 4) indicate that scarcity of resource have an important impact on the food demand, with the expected result that an increase in the shadow price of water, grazing, and crop residue reduces PCFE by $0.053 \%, 0.067 \%$, and $0.044 \%$, respectively. This implies that the scarcity has a negative effect on household PCFE either by affecting livestock production directly, affecting crop or off-farm income via labor reallocation or through its direct impact on time leisure consumption.

Regarding gender differential effects, Table 5 presents extra information on the gender differential effect of resource scarcity on PCFE and food security using both walking distance and shadow value indicators. For the sack of simplicity, only coefficients of variables of interests are reported. As of Table 5, the results show that a highly significant difference of PCFE and food security between male and female is a result from a resource scarcity. Taking the results from the level value, an increase in the traveling distance of the water, grazing, and transporting distance of crop residue reduces men's PCFE by $0.149 \%, 0.101 \%$, and $0.078 \%$, respectively, but has no significant effects on female's PCFE. Likewise, a $1 \%$ increase in minutes traveled to search water, reach grazing, and collect crop residue leads to $0.080 \%$,

Table 5 Effect of water, grazing, and feed scarcity on log PCFE and food security

\begin{tabular}{|c|c|c|c|c|c|c|}
\hline \multirow[t]{2}{*}{ Variables } & \multicolumn{3}{|l|}{ PCFE } & \multicolumn{3}{|c|}{ Food security } \\
\hline & $\overline{\text { All }}$ & Male & Female & $\overline{\text { All }}$ & Male & Female \\
\hline \multicolumn{7}{|l|}{ A. Walking distance } \\
\hline \multirow[t]{2}{*}{ Ln(WaterD) } & $-0.131^{* * *}$ & $-0.1492^{* * *}$ & -0.0607 & $-0.0839^{* * *}$ & $-0.0803^{*}$ & -0.0978 \\
\hline & $(0.0320)$ & $(0.0366)$ & $(0.0665)$ & $(0.0291)$ & $(0.0324)$ & $(0.0762)$ \\
\hline \multirow[t]{2}{*}{ Ln(GrazingD) } & $-0.0888^{* *}$ & $-0.1008^{* *}$ & -0.0339 & $-0.1190^{* * *}$ & $-0.1160^{* * *}$ & $-0.1507^{*}$ \\
\hline & $(0.0347)$ & $(0.0406)$ & $(0.0724)$ & $(0.0335)$ & $(0.0384)$ & $(0.0901)$ \\
\hline \multirow[t]{2}{*}{$\operatorname{Ln}($ FeedD) } & $-0.0716^{* * *}$ & $-0.0779^{* * *}$ & -0.0394 & $-0.0708^{* * *}$ & $-0.0603^{* *}$ & $-0.0822^{*}$ \\
\hline & $(0.0248)$ & $(0.0287)$ & $(0.0497)$ & $(0.0234)$ & $(0.0277)$ & $(0.0495)$ \\
\hline Observations & 496 & 370 & 126 & 514 & 382 & 132 \\
\hline \multicolumn{7}{|l|}{ B. Shadow value } \\
\hline \multirow[t]{2}{*}{ Ln(ShadowPW) } & $-0.0528^{*}$ & -0.0497 & -0.0550 & $-0.0594^{*}$ & -0.0432 & $-0.1447^{*}$ \\
\hline & $(0.0303)$ & $(0.0352)$ & $(0.0616)$ & $(0.0327)$ & $(0.0373)$ & $(0.0878)$ \\
\hline \multirow[t]{2}{*}{ Ln(ShadowPG) } & $-0.0669^{* *}$ & $-0.0706^{* *}$ & -0.0358 & $-0.0533^{*}$ & -0.0513 & -0.0864 \\
\hline & $(0.0312)$ & $(0.0352)$ & $(0.0705)$ & $(0.0307)$ & $(0.0357)$ & $(0.0659)$ \\
\hline \multirow[t]{2}{*}{ Ln(ShadowPF) } & $-0.0441^{* *}$ & $-0.0536^{* * *}$ & -0.0082 & $-0.0418^{* *}$ & $-0.0416^{*}$ & -0.0330 \\
\hline & $(0.0178)$ & $(0.0203)$ & $(0.0392)$ & $(0.0185)$ & $(0.0215)$ & $(0.0394)$ \\
\hline Observations & 496 & 370 & 126 & 514 & 382 & 132 \\
\hline
\end{tabular}


$0.116 \%$, and $0.060 \%$ decrease in food security for male and $0.151 \%$ and $082 \%$ decrease in food security for female.

A similar pattern is revealed when analyzing differential effects of resource scarcity using shadow vale scarcity indicator (Table 5). These results suggest that an increase in the shadow price of grazing and straw reduces men's PCFE by $0.071 \%$ and $0.054 \%$ but does not affect female's PCFE. Moreover, an increase in the shadow price of straw and water results in a reduction of $0.042 \%$ in food security for male and $0.145 \%$ in food security for female. These results are an indication that we find a differential effect between male and female. The negative coefficients for the scarcity indicators signal low PCFE and food security, with a male are considerably likely to have less food consumption expenditure and being food insecure more as compared to female households. This goes in line with the reality in the ground that searching and collecting these scarce resources in the study area are mainly the duty of men. Male spend more labor than female to search and collect these resources.

This result agrees with the finding of Bandyopadhyay et al. (2011) whose result revealed that scarcity of biomass negatively affected rural PCFE in Malawi. Baland et al. (2010) also showed that an increase in firewood collection time by $1 \mathrm{~h}$ is equivalent to an income loss of about 1\% in Nepal. Bhattacharya and Innes (2006) highlighted that forest degradation spurs rural poverty in Sub-Saharan Africa. This supports the argument by Chopra et al. (2007), Cooke et al. (2008), Kumar and Hotchkiss (1988), and Tangka and Jabbar (2005), whose study conclude that feed and water scarcity reduces livestock, crop, and non-farm productivity as well as access to food, resulting in less food security and low human welfare by traveling long distance with an animal in search of feed and water in less developing countries.

Estimation with regard to the food security is presented in Table 6, the model had about $38 \%$ prediction as compared to $48 \%$ observed probability. The negative significant relationship between the shadow prices and the household food security implies that household who spend more time on searching water, grazing, and crop residue are more likely to be food insecure than their counterpart with nearer distance. The coefficients from marginal effect indicated that increasing the shadow prices of water, grazing, and crop residue reduces the probability of food security by $0.0594 \%, 0.0533 \%$, and $0.0418 \%$, respectively, supporting the arguments forwarded by Cooke et al. (2008) and Mekonnen et al. (2015). The results further show that the probability of food security increases significantly and consistently with farm output, total income, and religion in favor of (Ogundari 2017) but declines with family and herd size, supporting the results from (Feleke et al. 2005).

The hypothesis that the impact of feed and water scarcity strongly increase from the bottom (poor) to the top (rich) quantile is tested using quantile regression results displayed in Table 7. Surprisingly, time spent looking for water and grazing land has resulted in a negative sign as expected and it is found to be an important factor in per capita food expenditure. The impact of a $1 \%$ increase in distance to grazing and crop residue source brings about a $0.171 \%$ and $0.069 \%$ reduction in food expenditure only for the top category while the effect of water is $0.064 \%$ at the median value. This supports the argument by Tangka and Jabbar (2005), whose study concluded that feed scarcity reduces livestock, crop, and non-farm productivity as well as access to food, resulting in less food insecurity and low human welfare by traveling long distance with the animal in search of feed and water in less developing countries. 
Table 6 Probit estimation of food security using walking distance

\begin{tabular}{|c|c|c|c|}
\hline \multirow[t]{2}{*}{ Variables } & (ME) & (ME) & (ME) \\
\hline & HHFS & HHFS & HHFS \\
\hline \multirow[t]{2}{*}{ Ln(output) } & $0.0280^{* *}$ & $0.0315^{* *}$ & 0.0153 \\
\hline & $(0.0134)$ & $(0.0140)$ & $(0.0145)$ \\
\hline \multirow[t]{2}{*}{ Ln(livestock) } & $-0.0257^{* *}$ & $-0.0236^{*}$ & $-0.0269^{* *}$ \\
\hline & $(0.0120)$ & $(0.0122)$ & $(0.0121)$ \\
\hline \multirow[t]{2}{*}{ Ln(Family size) } & $-0.203^{* * *}$ & $-0.202^{* * *}$ & $-0.206^{* * *}$ \\
\hline & $(0.0591)$ & $(0.0596)$ & $(0.0598)$ \\
\hline \multirow[t]{2}{*}{ Gender(1/0) } & -0.0880 & -0.0596 & -0.0853 \\
\hline & $(0.0670)$ & $(0.0669)$ & $(0.0668)$ \\
\hline \multirow[t]{2}{*}{ Information(1/0) } & 0.0629 & 0.0358 & 0.0506 \\
\hline & $(0.0584)$ & $(0.0592)$ & $(0.0585)$ \\
\hline \multirow[t]{2}{*}{ Location(1/0) } & -0.0963 & -0.126 & -0.169 \\
\hline & $(0.146)$ & $(0.134)$ & $(0.124)$ \\
\hline \multirow[t]{2}{*}{ Ln(marketD) } & -0.0447 & -0.0540 & -0.0409 \\
\hline & $(0.0376)$ & $(0.0379)$ & $(0.0374)$ \\
\hline \multirow[t]{2}{*}{ Shock13(1/0) } & -0.138 & -0.155 & -0.151 \\
\hline & $(0.197)$ & $(0.187)$ & $(0.189)$ \\
\hline \multirow[t]{2}{*}{ Ln(shocks) } & 0.355 & $0.404^{*}$ & $0.395^{*}$ \\
\hline & $(0.240)$ & $(0.219)$ & $(0.224)$ \\
\hline \multirow[t]{2}{*}{ Religion(1/0) } & $0.147^{* *}$ & $0.135^{* *}$ & $0.135^{* *}$ \\
\hline & $(0.0649)$ & $(0.0653)$ & $(0.0653)$ \\
\hline \multirow[t]{2}{*}{ Network(1/0) } & -0.0703 & -0.0419 & -0.0482 \\
\hline & $(0.0645)$ & $(0.0640)$ & $(0.0636)$ \\
\hline \multirow[t]{2}{*}{ Age(years( } & -0.000700 & -0.000232 & -0.000741 \\
\hline & $(0.00185)$ & $(0.00185)$ & $(0.00185)$ \\
\hline \multirow[t]{2}{*}{ Ln(income) } & $0.0327^{* * *}$ & $0.0321^{* * *}$ & $0.0324^{* * *}$ \\
\hline & $(0.00293)$ & $(0.00293)$ & $(0.00295)$ \\
\hline \multirow[t]{2}{*}{ Ln(ShadowPW) } & $-0.0594^{*}$ & & \\
\hline & $(0.0327)$ & & \\
\hline \multirow[t]{2}{*}{ Ln(ShadowPG) } & & $-0.0533^{*}$ & \\
\hline & & $(0.0307)$ & \\
\hline \multirow[t]{2}{*}{ Ln(ShadowPF) } & & & $-0.0418^{* *}$ \\
\hline & & & $(0.0185)$ \\
\hline Observed probability & 0.4824 & 0.4792 & 0.4824 \\
\hline Predicted probability & 0.3803 & 0.3723 & 0.3792 \\
\hline Pseudo $R^{2}$ & 0.4379 & 0.4404 & 0.4405 \\
\hline Observation & 514 & 514 & 514 \\
\hline
\end{tabular}

$P$ values are for slopes: ${ }^{* *} P<0.01,{ }^{* *} P<0.05$, and ${ }^{*} P<0.10=$ significant at $1 \%, 5 \%$, and $10 \%$ probability level, respectively

Total effect of feed and water scarcity on total welfare

This analysis finalizes its discussion by exploring the total effect of animal water and feed scarcity on total welfare. Based on the descriptive statistics in Table 1, the median household in this sample spends up to one $75 \mathrm{~min}$ to travel to a water source, $91 \mathrm{~min}$ to search for grazing land, and $577 \mathrm{~min}$ to transport crop residue 
Table 7 Effect of water, grazing, and feed scarcity on log PCFE using quantile regression

\begin{tabular}{llllll}
\hline Variables & (PCFE) & (PCFE) & (PCFE) & (PCFE) & (PCFE) \\
& $\mathrm{q} 10$ & $\mathrm{q} 25$ & $\mathrm{q} 50$ & $\mathrm{q} 75$ & $\mathrm{q} 90$ \\
\hline Ln(ShadowPW) & -0.00210 & -0.0102 & $-0.0644^{* *}$ & -0.0341 & -0.0299 \\
& $(0.0546)$ & $(0.0291)$ & $(0.0259)$ & $(0.0268)$ & $(0.0457)$ \\
Ln(ShadowPG) & -0.0608 & -0.0345 & $-0.100^{* * *}$ & $-0.0996^{* * *}$ & $-0.171^{* * *}$ \\
& $(0.0408)$ & $(0.0274)$ & $(0.0313)$ & $(0.0289)$ & $(0.0490)$ \\
Ln(ShadowPF) & -0.0413 & -0.00441 & -0.00858 & -0.0194 & $-0.0691^{* * *}$ \\
& $(0.0372)$ & $(0.0247)$ & $(0.0181)$ & $(0.0165)$ & $(0.0260)$ \\
Observations & 496 & 496 & 496 & 496 & 496 \\
\hline
\end{tabular}

$P$ values are for slopes: ${ }^{* *} P<0.01$ and ${ }^{* *} P<0.05=$ significant at $1 \%$ and $5 \%$ probability level, respectively

yearly. The labor hours allocated for these scarce resources then reduces the total time available for crop farming activities in addition to the reduction on the households' leisure consumption. Its effect on agricultural production is investigated via the production sector and its direct impact on household's utility analyzed through consumption sector. The aggregate of the two shows the total welfare effect on the household's livelihood.

Based on Eq. (12), the total effect is simply calculated by taking the slope coefficient of income $\left(\frac{d C_{d}}{d Y}\right)$ in the consumption regression multiplied by the coefficient of time allocation in the production estimation $\left(\frac{d Y}{d L_{c}}\right)$, plus the coefficient of time allocation in the consumption regression $\left(\frac{d C_{d}}{d L_{c}}\right)$. Based on Table 8, the total impact of time spent searching for water, feed, and collecting straw on per PCFE is $-0.142 \%$, $-0.102 \%$, and $-0.092 \%$, respectively, using distance measure. This implies that for a $1 \%$ increase in minutes traveled to a water, grazing, and straw source, PCFE decreases by $0.142 \%, 0.102 \%$, and $0.092 \%$, respectively. If the median household in this data spends about $60 \mathrm{~min}$ daily to look for water and feed source and have PCFE 2490 ETB, decreasing traveling minutes to a water, grazing, and straw source by 0.6 min daily will increase PCFE by 354 ETB, 254 ETB, and 229 ETB, respectively, for the median household using panel A distance value (Table 8). The estimate for the production is available upon request.

Table 8 Aggregate effect of water and feed scarcity on output, food expenditure, and food security

\begin{tabular}{llll}
\hline Estimates & Effect on output $(Y)$ & Effect on PCFE & Total effect \\
\hline Panel A using distance value & $\frac{d Y}{d T}$ & $\frac{d P C F E}{d T}$ & $\frac{d P C F E}{d Y} \frac{d Y}{d T}+\frac{d P C F}{d T}$ \\
Water scarcity $\left(T_{w}\right)$ & -0.155 & -0.133 & -0.142 \\
Grazing scarcity $\left(T_{f}\right)$ & -0.279 & -0.086 & -.102 \\
Straw scarcity $\left(T_{t}\right)$ & -0.328 & -.0731 & -.092 \\
Panel B using shadow price & & & \\
Water scarcity $\left(T_{w}\right)$ & -0.074 & -0.0529 & -.057 \\
Grazing scarcity $\left(T_{f}\right)$ & -0.094 & -0.0627 & -.068 \\
Straw scarcity $\left(T_{t}\right)$ & -0.154 & -0.0421 & -.051 \\
\hline
\end{tabular}




\section{Conclusion and suggestion}

The scarcity of grazing and water for an animal has a negative effect on households' welfare and food security either by affecting livestock production directly, affecting crop or off-farm income via labor reallocation or through its direct impact on time leisure consumption. Our research questions focus on the relationship between natural resource scarcity and PCFE (welfare) and food security (Table 8). In this paper, we have explored these effects using distance and shadow price as resource scarcity indicators in Northern Ethiopia based on 518 sample farmers. To address our research first objective, we employed the IV-2SLS estimation, and the second question is addressed by estimating a probit model for food security. The descriptive result shows that about $48 \%$ of the households were food secure while $52 \%$ were food insecure given the two thirds of the average of all household's PCFE is 1660 ETB.

Our results confirmed the theoretical prediction that resource scarcity affects households' welfare and food security adversely as predicted by the downward spiral hypothesis (Ostrom et al. 1999). The results in this paper provide an interesting picture of smallholders in Ethiopia and hint at several areas that could be important for improving food security and welfare in general. As expected, it appears that time spent looking for water and feed has a significant and negative effect on PCFE and food security. In aggregate, reducing time spent looking for water by $1 \%$ leads to an increase in PCFE by $0.131 \%$ and food security by $0.0594 \%$. Similarly, a $1 \%$ decrease in time wastage for searching grazing land increase PCFE and aggregate food security by $0.088 \%$ and $0.053 \%$, respectively, and an increment of $0.0716 \%$ in PCFE and $0.0418 \%$ in food security is achieved by $1 \%$ reduction in crop residue transporting time per a single trip.

The total impact of time spent searching for water, feed, and collecting straw on per PCFE is $-0.142 \%,-0.102 \%$ and $-0.092 \%$, respectively, using distance measure, and decreasing traveling minutes to a water, grazing, and straw source by $0.6 \mathrm{~min}$ will increase PCFE by 354 ETB, 254 ETB, and 229 ETB for the median household. Depending on results from the quantile regression, the effect of water and feed scarcity is not uniform across the food consumption distribution. A similar pattern is revealed when analyzing differential effects of resource scarcity. The results suggest that an increase in the traveling distance of water, grazing, and transporting distance of crop residue reduces men's PCFE by $0.149 \%, 0.101 \%$, and $0.078 \%$ but have no significant effects on female's PCFE. Likewise, a $1 \%$ increase in minutes traveled to search the water, reach grazing, and collect crop residue leads to $0.080 \%, 0.116 \%$, and $0.060 \%$ decrease in food security for male and $0.151 \%$ and $082 \%$ decrease in food security for female. The negative coefficients for the scarcity indicators signal low PCFE and food security, with a male are considerably likely to have less food consumption expenditure and being food insecure more as compared to female households.

Our study plays a great role in the understanding of the linkages between welfare, food security, and environmental resources such as grazing and water scarcity. In general, this study can be helpful for policymakers working to alleviate animal water and feed problems in Ethiopia to justify their actions with an empirical result. Besides, this study's result can give a good lesson for policy analysts that labor allocation for reaching water and feed source imposes a negative impact on on-farm farmers' agricultural output and food consumption and hence on food security by displacing productive labor away from productive activities. Since the effect of these scarce resources is not 
uniform between poor and rich or between male- and female-headed farmers. A nearby water and feed source does not only alleviate labor constraints, but also saves energy and time that could be used for other productive farming activities.

Two areas of policy intervention can be emerged as relevant. The first involves policies and institutions that facilitate easier access to animal water tap by advocating on emergency relief grounds. The second area of policy intervention involves the introduction of more efficient animal feed management strategy that can improve cattle production and reduce land degradation. A policy that sought to increase aggregate production or that which sought to increase household food consumption would greatly impact the highest quantile more than those who are in the lowest quantile of food production distribution. Future research should focus on adopting an approach using other welfare indicators (nutrition, incidences of malnourishment, daily calorie intake, and diversity of food intake) to proxy food security than per capita food expenditure. In addition, a research that uses a lag value of crop output than current output in the per capita food expenditure estimation based on longitudinal data will be a plus for this paper.

\section{Endnotes}

${ }^{1}$ See for a similar approach in the work of (Baland et al. 2010; Cooke 1998; and Cooke et al. 2008).

${ }^{2}$ For a detail review of related empirical studies, see Cooke et al. (2008).

${ }^{3}$ See for a similar approach in the work of (Smith and Subandoro 2007; Gaiha et al. 2014; Mignouna et al. 2015; Çağlayan and Astar 2012).

${ }^{4} \mathrm{NMBU}-\mathrm{MU}$ refers to the Norwegian University of Life Science-Mekelle University.

${ }^{5}$ Check the work of Asfaw et al. (2012) and Thirumarpan (2013) for similar work.

${ }^{6}$ Thirumarpan (2013) and Asfaw et al. (2012) used consumption expenditure to reflect the socio-economic welfare of household and is a reliable indicator of food accessibility and degree of vulnerability to food insecurity.

${ }^{7}$ The same approach is found in the work of Titus and Adetokunbo (2007).

${ }^{8}$ In order to adjust for big variation in the wage rate among villages of the region, the wage rate is adjusted using a general informal rural labor conversion factor, 0.98 .

\section{Acknowledgements}

This research has been sponsored by the collaborative research and capacity-building project on Climate Smart Natural Resource Management and Policy (NORHED-CLISNARP) between Mekelle University and Norwegian University of Life Sciences. The NORHED-CLISNARP project and this research are funded by the Norwegian Agency for Development Cooperation (NORAD) and the Quota Scholarship Programme of StatensLånekasse for Utdanning. Special thanks go to my Supervisor Professor Stein Holden (NMBU), Norway, for his unreserved advisorship and my Co-advisor Dr. Mesfin Tilahun (Mekelle University) for his assistance.

Funding

This research was funded by the Norwegian Agency for Development Cooperation (NORAD) and the Quota Scholarship Programme of StatensLånekasse for Utdanning during field work.

Availability of data and materials

The dataset used in this paper is available and accessible upon request from the corresponding author.

Author's contributions

The single author revised and approved the final submitted manuscript. 


\section{Publisher's Note}

Springer Nature remains neutral with regard to jurisdictional claims in published maps and institutional affiliations.

\section{Received: 5 October 2017 Accepted: 24 October 2018}

Published online: 05 December 2018

\section{References}

Abdulai A, Huffman W (2014) The adoption and impact of soil and water conservation technology, an endogenous switching regression application. Land Econ 90:26-43.

Adewuyi SA, Mafimisebi TE, Awe PO (2009) Food expenditure patterns among urban households in Ibadan Southwest Local Government Area, Oyo State. J Humanities Soc Sci Creative Arts 4:82-89.

Aggrey N, Wambugu S, Karugia J, Wanga E (2010) An investigation of the poverty-environmental degradation nexus: a case study of Katonga Basin in Uganda. Research Journal of Environmental and Earth Sciences 2:82-88.

Aluko MAO (2004) Sustainable development, environmental degradation and the entrenchment of poverty in the Niger Delta of Nigeria. J Hum Ecol 15:63-68.

Angrist JD, Evans W (1998) Children and their parents' labor supply: evidence from exogenous variation in family size. Am Econ Rev 88:450-477.

Arnold M, Kohlin G, Persson R, Shepherd G (2003) Fuelwood revisited-what has changed in the last decade? Center for International Forestry Research (CIFOR), Occasional Paper No. 39.

Asfaw S, Shiferaw B, Simtowe F, Lipper L (2012) Impact of modern agricultural technologies on smallholder welfare: evidence from Tanzania and Ethiopia. Food Policy 37:283-295.

Asresie A, Zemedu L (2015) The contribution of livestock sector in Ethiopian economy. A review. Advances Life Sci Technol 29:9-90.

Babalola DA, Isitor SU (2014) Analysis of the determinants of food expenditure patterns among urban households in Nigeria: evidence from Lagos State. J Agriculture Veterinary Sci 7:71-75.

Baland JM, Bardhan P, Das S, Mookherjee D, Sarkar R (2010) The environmental impact of poverty: evidence from firewood collection in rural Nepal. Econ Dev Cult Chang 59:23-61.

Bandyopadhyay S, Shyamsundar P, Baccini A (2011) Forests, biomass use and poverty in Malawi. Ecol Econ 70:2461-2471.

Becker GS (1981) Treatise on the family. Harvard University Press, Cambridge.

Belay D, Getachew E, Azage T, Hegde BH (2013) Farmers' perceived livestock production constraints in Ginchi watershed area: result of participatory rural appraisal. Int J Livestock Prod 4:128-134.

Bewket W (2011) Farmers knowledge of soil erosion and control measures in the northern highlands of Ethiopia. Af Geographical Rev 30:53-70.

Bezabih MY, Berhane G (2014) Livestock production systems analysis. Am Int J Contemp Sci Res 1:16-51.

Bezu S, Kassie GT, Shiferaw B, Ricker-Gilbert J (2014) Impact of improved maize adoption on welfare of farm households in Malawi: a panel data analyses. World Dev 59:120-131.

Bhattacharya H, Innes R (2006) Is there a nexus between poverty and environment in rural India? AAEA Annual Meeting, Long Beach.

Bishu KG (2014) Risk management and the potential of cattle insurance in Tigray, Northern Ethiopia. PhD Thesis. University College Cork.

Boone C, Glick P, Sahn DE (2011) Household water supply choice and time allocated to water collection: evidence from Madagascar. J Dev Stud 47:1826-1850.

Çağlayan E, Astar M (2012) A micro-econometric analysis of household consumption expenditure determinants for both rural and urban areas in Turkey. Am Int J Contemp Res 2:27-34.

Chopra N, Singh S, Gupta S, Narain U, Veld KVT (2007) Who Collects Resources in Degraded Environment? A Case Study from Jhabua District, India. SANDEE Working Paper No. 23-07.

Cooke P, Köhlin G, Hyde WF (2008) Fuelwood, forests, and community management - evidence from household studies. Environ Dev Econ 13:103-135.

Cooke PA (1998) The effect of environmental good scarcity on own-farm labor allocation: the case of agricultural households in rural Nepal. Environ Dev Econ 3:443-469.

Damte A, Koch SF, Mekonnen A. (2012) Coping with fuelwood scarcity. Household responses in rural Ethiopia. Environment for Development. Discussion Paper Series 12-01.

Dasgupta P (2007) Nature and the economy. J Appl Ecol 44:475-487.

Dercon S (2004) Growth, and shocks: evidence from rural Ethiopia. J Dev Econ 74:309-329.

Dercon S, Hoddinott J, Woldehanna T (2005) Shocks and consumption in 15 Ethiopian villages, 1999-2004. J Afr Econ 14:559-585.

Di Falco S, Veronesi M, Yesuf M (2011) Does adaptation to climate change provide food security? A micro-perspective from Ethiopia. Am J Agric Econ 93:829-846.

Faridi R, Wadood SN (2010) An econometric assessment of household food security in Bangladesh. Bangladesh Dev Stud:97-111.

Feleke ST, Kilmer RL, Gladwin CH (2005) Determinants of food security in Southern Ethiopia at the household level. Agric Econ 33:351-363.

Felleke G, Geda G (2001) The Ethiopian dairy development policy: a draft policy document. Ministry of Agriculture (MoA), Addis Ababa.

Freeman A, Kaitibie S, Moyo S, Perry B (2007) Livestock, livelihoods and vulnerability in selected SADC countries (Lesotho, Malawi and Zambia). International Livestock Research Institute (ILRI) Research Report, 8.

Gaiha R, Kaicker N, Imai K, Kulkarni VS, Thapa G (2014) Dietary shift and diet quality in India: an analysis based on 50 th, 61 st and 66 th rounds of NSS. Handbook on food: demand, supply, sustainability and security 177-203.

Gebreegziabher T, Nyssen J, Govaerts B, Getnet F, Behailu M, Haile M, Deckers J (2008) Contour furrows for in situ soil and water conservation, Tigray Northern Ethiopia. Soil Tillage Res 103:257-264.

Gebremedhin B (2009) Feed marketing in Ethiopia: results of rapid market appraisal. ILRI (aka ILCA and ILRAD), Paper No. 15. 
Hagos F (2003) Poverty, institutions, peasant behavior and conservation investment in Northern Ethiopia. Doctoral Dissertation. UMB School of Economics and Business. Norwegian University of Life Sciences. Dissertation no 2003:2.

Hidalgo FD, Naidu S, Nichter S, Richardson N (2010) Occupational choices: economic determinants of land invasions. Rev Econ Stat forthcoming.

Hoddinott J, Maluccio JA, Behrman JR, Flores R, Martorell R (2008) Effect of a nutrition intervention during early childhood on economic productivity in Guatemalan adults. Lancet 371:411-416.

Ilyin S (2011) The looming threat of overgrazing: effects and recommendations. Congressional Hunger Center. [online] http: / / Hungercenter.wpengine.netdna-cdn.com / wp-content Looming-Threat-of-Overgrazing-llyin.pdf (uploaded 09, 2011).

Khan $\mathrm{H}$ (2008) Poverty, environment and economic growth: exploring the links among three complex issues with specific focus on the Pakistan's case. Environment Development Sustainability 10:913-929.

Koenker R, Bassett G (1978) Regression quantiles. Econometrica 46:33-50.

Kumar SK, Hotchkiss D (1988) Consequences of deforestation for women's time allocation, agricultural production, and nutrition in hill areas of Nepal, research report 69. International Food Policy Research Institute, Washington, DC.

Lal R, Stewart BA (2010) Food security and soil quality. Advances in soil science.

Magnan N, Larson DM, Taylor JE (2012) Stuck on stubble? The non-market value of agricultural byproducts for diversified farmers in Morocco. Am J Agric Econ 94:1055-1069.

Matchaya G, Chilonda P (2012) Estimating effects of constraints on food security in Malawi: policy lessons from regressions quantiles. Appl Econ Int Dev 12:165-191.

Mekonnen A, Damte A, Deribe R (2015) The impact of natural resource scarcity on agriculture in Ethiopia, The environment for Development Discussion Paper-Resources for the Future (RFF) 15-13.

Mekonnen D, Bryan E, Alemu T, Ringler C (2017) Food versus fuel: examining tradeoffs in the allocation of biomass energy sources to domestic and productive uses in Ethiopia. Agric Econ 0:1-11.

Mignouna DB, Abdoulaye T, Alene A, Manyong VM, Dontsop PN, Ainembabazi JH, Asiedu R (2015) A Microecnometrics Analysis of Household Consumption Expenditure Determinants in Yam-Growing Areas of Nigeria and Ghana. Tropicultura 33(3):226-237.

Narain U, Gupta S, Van't Veld K (2008) Poverty and the environment: exploring the relationship between household incomes, private assets, and natural assets. Land Econ 84:148-167.

Njimanted GF (2006) Econometric model of poverty in Cameroon: a system estimation approach. Int Review Bus Res Papers 2:30-46.

Ogundari K (2017) Categorizing households into different food security states in Nigeria: the socio-economic and demographic determinants. Agric Food Econ 5:8.

Oldiges C (2012) Cereal consumption and per capita income in India. Econ Polit Wkly 47:63.

Ostrom E, Burger J, Field CB, Norgaard RB, Policansky D (1999) Revisiting the commons: local lessons. Global Challenges Sci 284:278-282.

Oum TH (1989) Alternative demand models and their elasticity estimates. J Transp Econ Policy 23(2):163-187.

Palmer C, MacGregor J (2009) Fuelwood scarcity, energy substitution, and rural livelihoods in Namibia. Environ Dev Econ 14:693-715.

Randolph TF, Schelling E, Grace D, Nicholson CF, Leroy JL, Cole DC, Ruel M (2007) Role of livestock in human nutrition and health for poverty reduction in developing countries. J Anim Sci 85:2788-2800.

Sarris A, Savastano S, Christiaensen L (2006). The role of agriculture in reducing poverty in Tanzania: a household perspective from rural Kilimanjaro and Ruvuma, FAO Commodity and Trade Policy Research Working Paper No.19.

Sileshi Z, Tegegne A, Tsadik GT (2003) Water resources for livestock in Ethiopia: Implications for research and development, integrated water and land management research and capacity building priorities for Ethiopia, Research paper No.66.

Smith LC, Subandoro A (2007) Measuring food security using household expenditure surveys, vol 3. International Food Policy Research Institute, Washington, D.C..

Steinfeld H, Gerber P, Wassenaar TD, Castel V, de Haan C (2006) Livestock's long shadow: environmental issues and options. Food \& Agriculture Organization (FAO).

Stock JH, Yogo M (2005) Testing for weak instruments in linear IV regression. Ch. 5 Austin causal inference with observational data.

Strauss J (1983) Socioeconomic determinants of food consumption and production in rural Sierra Leone: Application of an agricultural household model with several commodities. MSU International Development Papers. Department of Agricultural Economics, Michigan State University, East Lansing, Michigan.

Strauss J (1986a) Estimating the Determinants of Food Consumption and Caloric Availability in Rural Sierra Leone". In I. Singh, L. Squire, and J. Strauss eds., Agricultural Household Models: Extensions, Applications, and Policy. Baltimore: Johns Hopkins University Press 116-152.

Swanepoel F, Stroebel A, Moyo S (2010) The role of livestock in developing communities: enhancing multifunctionality. Copublished by the Technical Centre for Agricultural and Rural Cooperation (CTA). South Africa, ISBN: 978-0-86886- 7984.

Tangka FK, Jabbar MA (2005) Implications of feed scarcity for gender roles in ruminant livestock production, Paper No. 182872.

Tegegne SD (2012) Livestock water productivity (LWP) improvement in the mixed crop-livestock system of Ethiopian Highlands, Amhara Region: a gendered sustainable livelihood approach to target LWP interventions for rural poverty reduction. ZEF.

Tesfa A, Mekuriaw S (2014) The effect of land degradation on farm size dynamics and crop-livestock farming system in Ethiopia: a review. Open J Soil Sci 4:1.

Thirumarpan K (2013) Determinants of household food expenditure among rural households of Ampara District. Proceedings, 04th International Symposium, SEUSL, Social Science and Humanities 325-330.

Tilahun H, Schmidt E (2012). Spatial analysis of livestock production patterns in Ethiopia, Development Strategy and Governance Division, International Food Policy Research Institute (IFPRI) - Ethiopia Strategy Support Program II (ESSP II), Working Paper 44, IFPRI, Addis Ababa.

Titus B, Adetokunbo G (2007) An analysis of food security situation among Nigerian urban households: evidence from Lagos State. Nigeria Journal of Central European Agriculture 8:397-406.

Wooldridge JM (2009) Introductory econometrics: a modern approach, 4th edn. South-Western SENGAGE Learning, Mason.

World Bank (2012) Word development indicators 2012. The World Bank, Washington DC.

Yilma Z, Guernebleich E, Sebsibe A, Fombad R (2011) A review of the Ethiopian dairy sector. Addis Ababa, Ethiopia, FAO SubRegional Office for Eastern Africa (FAO/SFE).

Yimer AA (2005) Farm management in mixed crop-livestock systems in the Northern Highlands of Ethiopia. PhD Thesis, Wageningen University. 